\title{
Information-theoretic analysis of a dynamic release site using a two-channel model of depression
}

\author{
Mehrdad Salmasi ${ }^{1,2^{*}}$, Martin Stemmler ${ }^{3,4}$, Stefan Glasauer ${ }^{1,2,3,5}$, Alex Loebel ${ }^{3,4}$ \\ From 24th Annual Computational Neuroscience Meeting: CNS*2015 \\ Prague, Czech Republic. 18-23 July 2015
}

Synapses are dynamic communication channels between neurons as their rates of information transfer depend on past history. While information theory has been used to study the information efficacy of synapses [1-3], the effect of synaptic dynamics, including short-term depression and facilitation, on the information rate is not yet fully understood.

To reduce the complexity of the problem, we confine ourselves here to a single release site of the synapse. This allows us to analytically calculate the information transfer at the release site for a simple model of synaptic depression which is based on binary channels. The input of the model is a spike train, modeled by an independent identically distributed process $X=\left\{X_{i}\right\}_{i=1}^{\infty}$, where each $X_{i}$ has a Bernoulli distribution with $P\left(X_{i}=0\right)=\alpha$. The model's output is a process $Y=\left\{Y_{i}\right\}_{i=1}^{\infty}$, such that if there is a release at time, then $Y_{i}=1$ and otherwise $Y_{i}=0$. We model the short term depression by two binary asymmetric channels that represent the possible states of the release site: the 'recovered' state, when no release occurred in the previous time step (Figure 1a), and the 'used' state, following vesicle release (Figure 1b). In particular, we

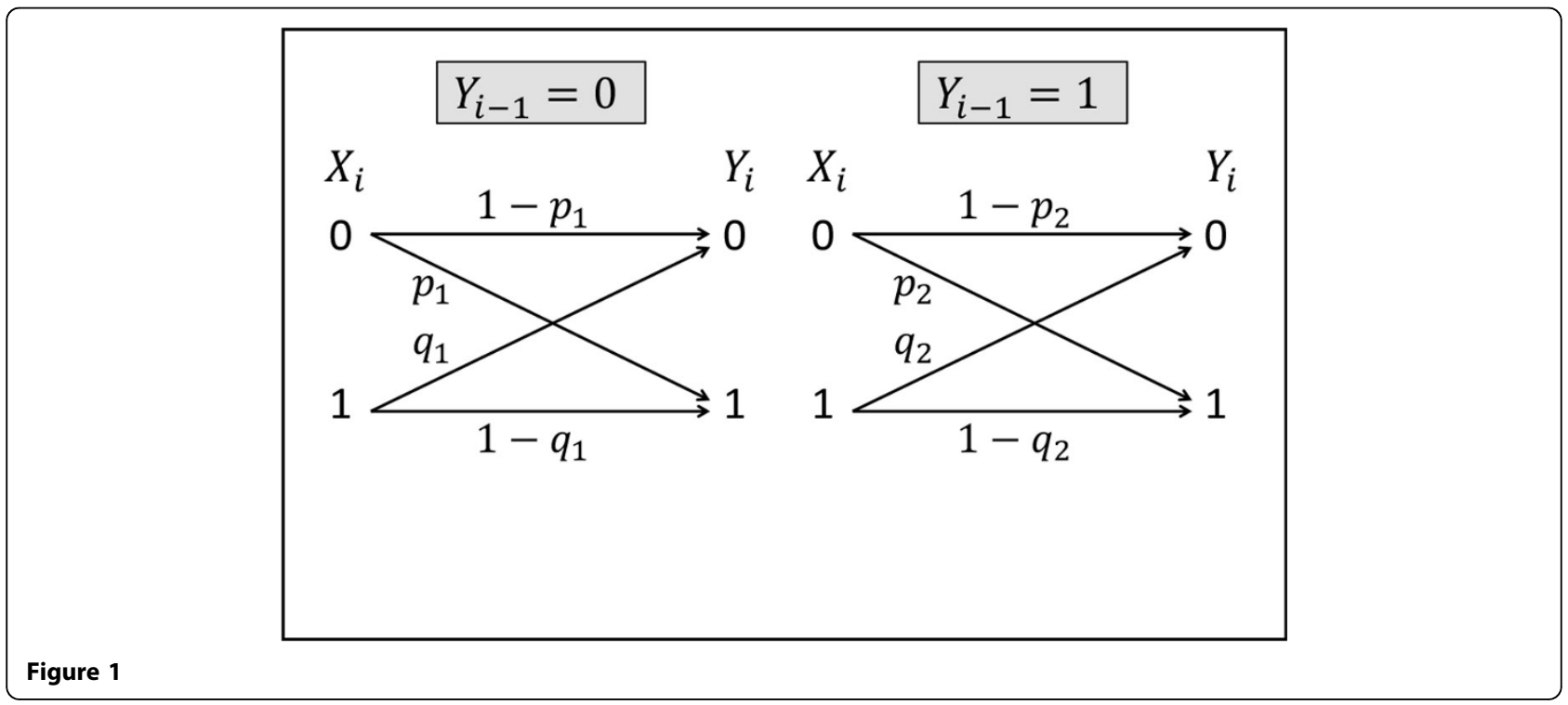

\footnotetext{
* Correspondence: mehrdad.salmasi@|rz.uni-muenchen.de

${ }^{1}$ Graduate School of Systemic Neurosciences, Ludwig-Maximilian University,

Munich, Germany

Full list of author information is available at the end of the article
} 
assume that the release probability is reduced following a release, that is $p_{2} \leq p_{1}$ and $1-q_{2} \leq 1-q_{1}$.

Each individual channel in Figure 1 will have a mutual information rate, either $r_{1}$ or $r_{2}$. As $X_{i}$ is Bernoullidistributed, $\mathrm{r}_{\mathrm{i}}=\mathrm{h}\left(\alpha \mathrm{p}_{\mathrm{i}}+\bar{\alpha} \overline{\mathrm{q}_{\mathrm{i}}}\right)-\alpha \mathrm{h}\left(\mathrm{p}_{\mathrm{i}}\right)-\bar{\alpha} \mathrm{h}\left(\overline{\mathrm{q}_{\mathrm{i}}}\right)$ for $i=$ 1,2 , where $h(\cdot)$ is the entropy of a Bernoulli random variable and $\overline{\mathrm{x}}=1-\mathrm{x}$. We prove that the mutual information rate of the release site with depression is a linear summation of the information rates of these two channels. The mutual information rate $I(X ; Y)$ between the input process $X$ nd the output process $Y$, is $I(X ; Y)=\theta r_{1}+(1-\theta) r_{2}$ where $\theta=\frac{\alpha \overline{\mathrm{p}_{2}}+\bar{\alpha} \mathrm{q}_{2}}{\alpha\left(\mathrm{p}_{1}+\overline{\mathrm{p}_{2}}\right)+\alpha\left(\overline{\mathrm{q}_{1}}+\mathrm{q}_{2}\right)}$.

The closed form expression of the mutual information rate allows us to study the effect of depression analytically. Through simulations we show that for a range of parameters, depression improves the rate of information transfer at the release site. We also show that when the level of depression is increased (i.e., with smaller $p_{2}$ and larger $q_{2}$ ), the release site's information capacity is reached at lower input spike rates. Therefore, the optimal spike rate of the presynaptic neuron has a reverse relationship with the depression level of its release site. This means that synaptic depression can save energy while maintaining information rate. The two-channel model of release site is a building block for the construction of more precise models of synaptic transmission. These advanced models will enable us to evaluate and study the synaptic information rates analytically.

\section{Acknowledgement}

This work was supported by the BMBF grant 01EO1401 (German Center for Vertigo and Balance Disorders).

\section{Authors' details}

${ }^{1}$ Graduate School of Systemic Neurosciences, Ludwig-Maximilian University, Munich, Germany. ${ }^{2}$ German Center for Vertigo and Balance Disorders, Ludwig-Maximilian University, Munich, Germany. ${ }^{3}$ Bernstein Center for Computational Neuroscience, Munich, Germany. ${ }^{4}$ Department of Biology II, Ludwig-Maximilian University, Munich, Germany. ${ }^{5}$ Department of Neurology, Ludwig-Maximilian University, Munich, Germany.

Published: 18 December 2015

\section{References}

1. London M, Schreibman A, Häusser M, Larkum ME, Segev I: The information efficacy of a synapse. Nature Neuroscience 2002, 5(4):332-340.

2. Fuhrmann G, Segev I, Markram H, Tsodyks M: Coding of temporal information by activity-dependent synapses. Journal of Neurophysiology 2002, 87(1):140-148.

3. Goldman MS: Enhancement of information transmission efficiency by synaptic failures. Neural Computation 2004, 16(6):1137-1162.

doi:10.1186/1471-2202-16-S1-P149

Cite this article as: Salmasi et al.: Information-theoretic analysis of a dynamic release site using a two-channel model of depression. BMC Neuroscience 2015 16(Suppl 1):P149.

\section{Submit your next manuscript to BioMed Central and take full advantage of:}

- Convenient online submission

- Thorough peer review

- No space constraints or color figure charges

- Immediate publication on acceptance

- Inclusion in PubMed, CAS, Scopus and Google Scholar

- Research which is freely available for redistribution

Submit your manuscript at www.biomedcentral.com/submit
C Biomed Central 